\title{
Effect of heart rate on QT interval in children and adolescents
}

\author{
Seshadri Balaji, Yung R Lau, Paul C Gillette
}

\begin{abstract}
Objective-To study the effect of sympathetic stimulation and increase in heart rate on the QT and QTc intervals.

Design-Prospective non-randomised study of eight consecutive patients.

Setting-Electrophysiology laboratory at a tertiary centre.

Patients-Eight patients aged 10-20 years (median 12.5) undergoing repeat electrophysiological study after previously successful catheter ablation $(n=6)$ or presumed supraventricular tachycardia $(n=2)$ with negative studies.

Interventions-Electrocardiograms were obtained (a) at baseline, (b) during atrial pacing at $450 \mathrm{~ms}$ cycle length, (c) during isoprenaline infusion at $0.025 \mu \mathrm{g} / \mathrm{kg} / \mathrm{min}$, (d) adding atrial pacing (450 $\mathrm{ms}$ cycle length) to isoprenaline at $0.025 \mu \mathrm{g} / \mathrm{kg} / \mathrm{min}$, and (e) isoprenaline at $0.05 \mu \mathrm{g} / \mathrm{kg} / \mathrm{min}$.

Main outcome measures-QT and QTc intervals at each of the above mentioned stages.

Results-The QT interval was reduced from a mean value of $350 \mathrm{~ms}$ to around 315-325 ms by each of the above manoeuvres. Correspondingly, the QTc increased from a mean of $407 \mathrm{~ms}$ to around 445-470 ms. Pacing was as effective as isoprenaline in shortening the QT interval and prolonging the QTc intervals.

Conclusions-Heart rate directly influences QT and QTc intervals in children and adolescents. The $Q T$ is shortened, but QTc is prolonged. Hence, reliance on the QTc alone could lead to mistaken diagnosis of long QT syndrome.
\end{abstract}

(Heart 1997;77:128-129)

Keywords: QT interval; isoprenaline; electrocardiogram; heart rate

Previous reports on the effect of alterations of heart rate on the QT interval in adults have shown conflicting results. While some ${ }^{1}$ have seen a direct effect of heart rate on the QT interval, others ${ }^{2-4}$ have seen no such effect. The subject has gone largely unremarked in children and adolescents. We evaluated the effect of atrial pacing and $\beta$ adrenergic stimulation on the QT and QTc intervals in a group of children and adolescents.

\section{Patients and methods}

PATIENTS

Eight patients aged $10-20$ years (median $12 \cdot 5$ years) (six boys) were prospectively studied during electrophysiological (EP) evaluation. Six patients had previously undergone successful radiofrequency catheter ablation for supraventricular tachycardia, and the other two had EP studies for presumed supraventricular tachycardia but were found to be normal. All had normal cardiac structure by echocardiography. None had inducible arrhythmia at the time of the present study. Those who underwent ablations had their procedure performed through the atrial approach, and no lesions were placed on the ventricular myocardium. A previous study from our laboratory had shown no change in the repolarisation time (as measured by JT interval) in patients with WolffParkinson-White syndrome after successful ablation. ${ }^{5}$ Also, for this study, we used each patient as his or her own control. Informed consent was obtained from all parents of patients before the EP study.

Twelve-lead electrocardiograms (ECG) were obtained at resting baseline and during right atrial pacing at 133 beats/min (cycle length 450 $\mathrm{ms}$ ). An isoprenaline infusion was then begun at a dose of $0.025 \mu \mathrm{g} / \mathrm{kg} / \mathrm{min}$. After an interval of about $5 \mathrm{~min}$, when the heart rate was seen to have stabilised, a 12-lead ECG was obtained. Right atrial pacing was then performed again at the rate of 133 beats/min and, once again, after an interval of $5 \mathrm{~min}$ to allow stabilisation, another ECG was obtained. Finally, the dose of isoprenaline was increased to $0.05 \mu \mathrm{g} / \mathrm{kg} / \mathrm{min}$ and, after stabilisation of heart rate, another ECG was performed. Pacing was not performed at the $0.05 \mu \mathrm{g} / \mathrm{kg} / \mathrm{min}$ dose because the heart rate was often faster than 133 beats $/ \mathrm{min}$.

The ECG recordings were obtained at normal filtering $(0-100 \mathrm{~Hz})$ run at $50 \mathrm{~mm} / \mathrm{s}$ paper speed. In each recording, the RR interval and the QT interval were measured by hand, using calipers in six consecutive beats, and the mean value was calculated. The QT was measured in lead II as recommended by Moss et al. ${ }^{6}$ The QTc was calculated using Bazett's formula:

$$
\mathrm{QTc}=\frac{Q T}{\sqrt{R R}}
$$

\section{STATISTICAL ANALYSIS}

The data were analysed using analysis of variance (ANOVA) for repeated measures. If significance was noted, further analysis was performed by paired $t$ testing. A $\mathrm{P}$ value $<0.05$ was considered significant.

Results

The table summarises the RR, QT, and QTc intervals at the five phases of the study. 
Effect of pacing and isoprenaline on $R R, Q T$ and $Q T$ c intervals

\begin{tabular}{llll}
\hline & $\begin{array}{l}R R \text { (range) } \\
(m s)\end{array}$ & $\begin{array}{l}Q T \text { (range) } \\
(m s)\end{array}$ & $\begin{array}{l}Q T c \text { (range) } \\
(m s)\end{array}$ \\
\hline Control & $758(175)(570-1020)$ & $351(30)(310-400)$ & $407(16)(380-440)$ \\
Pacingt & 450 & $316(21)^{\star}(290-360)$ & $471(32)^{\star}(432-537)$ \\
Iso 0.025 & $543(120)(350-700)$ & $324(36)^{\star}(260-380)$ & $445(48)^{\star}(406-549)$ \\
Iso $0.025+$ pacingt & 450 & $317(20)^{\star}(300-340)$ & $472(29)^{\star}(447-507)$ \\
Iso 0.05 & $484(47)(440-580)$ & $320(28)^{\star}(280-360)$ & $460(29)^{\star}(417-501)$ \\
\hline
\end{tabular}

$\star \mathrm{P}<0.05$ compared with control value.

†Pacing at 133 beats/min (cycle length $450 \mathrm{~ms}$ ).

Iso, isoprenaline.

Values expressed as mean (SD) (range)

A significant shortening of the QT interval was noted at each manoeuvre compared with the baseline QT value. A significant simultaneous prolongation of the QTc was also noted. Furthermore, the RR interval with $0.05 \mu \mathrm{g} / \mathrm{kg} / \mathrm{min}$ of isoprenaline was nearly $450 \mathrm{~ms}$. Nevertheless, the QT interval was similar with isoprenaline and with pacing alone at $450 \mathrm{~ms}$. Thus at comparable heart rates, the QT and QTc were similar, whether the heart rate was achieved by pacing or by isoprenaline.

\section{Discussion}

Our study showed that heart rate directly influences the QT interval in children and adolescents. Previous studies on this subject in adults have shown conflicting results.

Ahnve and Vallin showed that heart rate can independently influence the QT interval, regardless of the presence of catecholamines. ${ }^{1}$ In their study, they used pacing and $\beta$ blockade to determine the effect of heart rate. ${ }^{1}$

Browne et al found that vagolytic drugs such as atropine can influence the QT interval, regardless of the heart rate. ${ }^{2}$ Rickards and Norman found that exercise-induced shortening of the QT interval was secondary to factors extrinsic to the heart rate. ${ }^{3}$ In their study, patients paced at rates comparable to physiological exercise showed only a small decrease in the QT interval. This was the rationale for the QT interval being used as a sensor for rateresponsive pacing.

Our results are more in keeping with those of Ahnve and Vallin. ${ }^{1}$ The QT interval was shortened by pacing at $450 \mathrm{~ms}$. Isoprenaline at a small dose $(0.025 \mu \mathrm{g} / \mathrm{kg} / \mathrm{min})$ shortened the QT interval to a comparable level. Superimposition of pacing at $450 \mathrm{~ms}$ on to this small dose of isoprenaline did not lead to further shortening of the QT interval. So, at comparable fast heart rates, the QT interval was similar regardless of whether isoprenaline or pacing or a combination of the two caused that heart rate. Thus our study shows that heart rate probably directly influences the QT interval.

The diagnosis of long QT syndrome can sometimes be difficult if the QTc is in the borderline range. Shimizu et al showed that manoeuvres that increase the heart rate can be used to differentiate patients with long QT syndrome from those without. ${ }^{7}$ Recently,
Vetter et al studied children with and without long QT syndrome. ${ }^{8}$ They showed that the QTc is prolonged by isoprenaline in patients with long QT syndrome who had a borderline QT (and QTc) on the resting ECG, whereas the QTc interval was not prolonged in normal patients. A similar response was also seen during atrial pacing in the two sets of patients. Our study shows that the QTc can be prolonged, even in children and adolescents, both by pacing and by isoprenaline. We believe that the QTc is prolonged secondary to the excessive heart rate effect of pacing and isoprenaline, which reduces the denominator in Bazett's equation. We believe, therefore, that to rely solely on QTc could lead to an erroneous diagnosis of long QT syndrome in patients with borderline QT and QTc.

Yet another implication of our study is in the use of rate-responsive pacemakers that have QT sensors. If heart rate alone can lead to shortening of the QT interval, this may lead to a positive feedback situation with unnecessary heart rate acceleration if a QT sensor is used. Further studies are required to clarify this issue before the use of the QT sensing as a viable means of rate-responsive pacing in children and adolescents.

In summary, we conclude that children and adolescents show a shortening of the QT and prolongation of QTc intervals with manoeuvres that increase heart rate, such as atrial pacing or isoprenaline. This response should be borne in mind when such manoeuvres are performed in individuals with a suspected diagnosis of long QT syndrome.

1 Ahnve S, Vallin $\mathrm{H}$. Influence of heart rate and inhibition of autonomic tone on the QT interval. Circulation 1982;65 435-9.

2 Browne KF, Zipes DP, Heger J, Prystowsky EN. Influence of the autonomic nervous system on the QT interval in man. Am f Cardiol 1982;50:1099-103.

3 Rickards AF, Norman J. Relation between QT interval and heart rate. New design of physiologically adaptive cardiac pacemaker. Br Heart $₹$ 1981;45:56-61.

4 Davidowski TA, Wolf S. The QT interval during reflex cardiovascular adaptation. Circulation 1984:69:22-5.

5 Salim MA, Case CL, Gillette PC. The JT interval as a "depolarization independent" measurement of repolar"depolarization independent" measurement of repolarization: lessons from catheter ablation of the Wolf

6 Moss AJ, Schwartz PJ, Crampton RS, Locati E, Carteen E Moss AJ, Schwartz PJ, Crampton RS, Locati E, Carteen E.
The long QT syndrome: a prospective international The long QT syndrome: a prosp
study. Circulation 1985;71:17-21.

7 Shimizu W, Ohe T, Kurita T, Shimomura K. Differential response of QTU interval to exercise, isoproterenol, and atrial pacing in patients with congenital long QT syn drome. PACE 1991;14:1966-70.

8 Vetter VL, Berul C, Sweeten TL. Exercise, pacing and isoproterenol [abstract]. Cardiol Young 1993;3:63. 